\title{
Analysis of "Miao Silver" Market Opportunities
}

\author{
Jingjing Liu \\ Tianjin Bohai Vocational Technology College, Tianjinaliujingjingei@163.com
}

\begin{abstract}
This article mainly revolves the unique cultural connotation of history has the unique Miao "Miao silver" analysis of market investigation, data, research and explore the "Miao silver" whether there is a market size, market research and investigation.
\end{abstract}

\section{Keywords-Miao silver; Analysis of silver market}

\section{ECONOMIC ENVIRONMENT ANALYSIS}

China sustained economic stability and rapid development in the past 20 years, China social consumption patterns in transition from subsistence to a type. Chinese jewelry market although young, but in a few short years has only American and Japan, leapt to the forefront of the world.

According to the statistical yearbook 2013, Tianjin region's GDP for the first time reached 1.1 yuan, a growth of $16.5 \%$. Investigation shows, Tianjin city, the second half of 2013 per capita of gold and silver jewelry consumption of 76 yuan, an increase of 3.1 times. At the same time, data show that Tianjin women over $80 \%$ have jewelry consumption demand. At the Tianjin gold and silver jewelry market, foreign brands to enter fully into low level, the domestic brand products limited, is not a clear brand positioning, product quality is uneven, so the "Miao silver" has a great market potential in the future of Tianjin.

"Miao silver" can fully tap the cultural connotation, by professional designers combine elements of fashion and the Miaos culture retro elements, through the complete planning of marketing research, "Miao silver" can realize the brand, can be established since the unique status has been in the minds of consumers, and even has become a strong Eastern culture details out of the country, the world of Chinese brand.

\section{CONSUMER BEHAVIOR ANALYSIS}

\section{A. The design of the questionnaire}

The design of the questionnaire mainly Tianjin market for gold and silver jewelry consumer demand, consumers for "Miao silver" product preference, "Miao silver jewelry sales place" main intention scope, from the investigation of basic information consumers began to ascertain the consumers to accept the "Miao silver" price interval end.

\section{B. Release and recovery of questionnaire investigation}

Select four locations in Tianjin (Tianjin Isetan gate, the road of friendship Huarun vanguard supermarket at the entrance, eight small Bai Lou Ronchamp street, Taiwan Culture Street) questionnaire ("Miao silver" Tianjin market survey questionnaire), issued 500 copies, 489 copies to recover.

\section{Data analysis}

The results of this survey analysis shows that Tianjin consumers like diversification Miao silver ornaments. The silver content in low price reasonable Miao silver ornaments of the most popular. The survey results (Figure 1) shows that consumers $25-40$ is the major consumer groups of Miao silver.

\section{Tianjin consumer miao silver age level analysis}

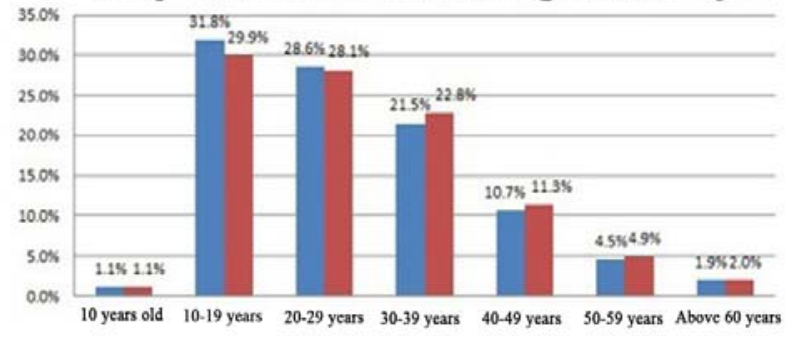

Figure 1. Analysis of Miao silver age level Tianjin consumer market

For acceptable Miao silver product price, the survey showed 500-10000 yuan products will become mainstream consumer products, it shows that all the different levels of consumer demand for silver Miao, Miao silver can become a popular demand for consumer goods.

In addition, the use of "5W1H" framework for the analysis of data are as follows:

5W1H-Who (target groups)

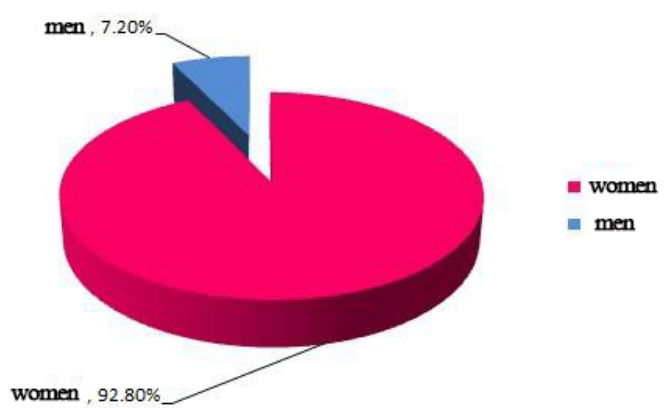

Figure 2. The questionnaire analysis -- Miao silver jewelry and women purchase intention ratio statistics

As shown in Figure 2, after the analysis of questionnaire, the jewelry consumption, women's groups bear the brunt, young women and middle-aged women, elderly women love jewelry.

5W1H-Where (consumer place): most women buy gold 
and silver jewelry in a large department store, select the number of online shopping and jewelry shop although it would be better to choose a large shopping mall, but the gap between them is very small. (Figure 3 )

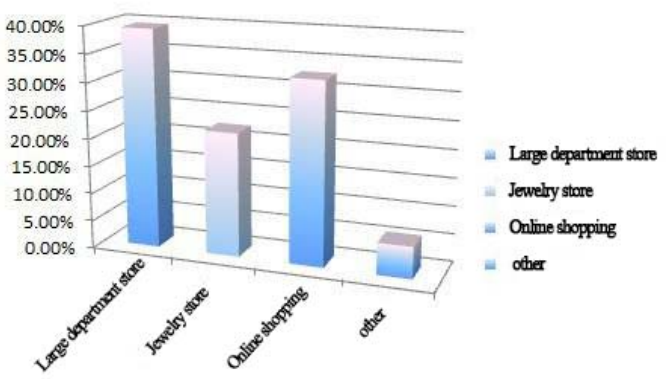

Figure 3. The questionnaire analysis -- silver jewelry purchase site statistics

5W1H-When (consumer opportunity): in Tianjin market to participate in the survey of consumers choose to send their $78.9 \%$ "'.

5W1H-How (production): credit card spending in particular credit card consumption has become the dominant form of women consumption.

\section{COMPETITOR ANALYSIS}

Analysis of "Miao silver" project of Potter's five forces model, specific as shown in table 1:

Introduction of

TABLE 1 "MIAO SILVER" PROJECT OF POTTER'S FIVE FORCES MODEL

\begin{tabular}{ll}
\hline Suppliers bargaining ability & $\begin{array}{l}\text { 1, "Miao silver" suppliers for the Miao Autonomous Region of the common people, Miao Autonomous District is relatively } \\
\text { closed, the removal of the more developed tourism industry, the local economy more poverty, limited bargaining power. } \\
\text { 2, In a few years this capital investment more and more heat, the silver becomes capital first to chase investment products, } \\
\text { large fluctuations in the price of silver, bring greater cost risk to the Miao silverware enterprises. }\end{array}$ \\
\hline $\begin{array}{l}\text { 1, the customer number of non professionals, and many do not understand the Miao silverware, bargaining power co.. } \\
\text { 2, the current number of silver jewelry sellers, the popularization of the Internet has greatly improved customer inquiry } \\
\text { ability. }\end{array}$
\end{tabular}
ability.

The replacement pressure

online stores despite the reduced customer time cost, similar product quality uneven, prices vary, leading to consumers could not form relative brand loyalty, as the Miao silverware enterprises, the competition pressure is very great.

\begin{abstract}
The existing competitive pressure

1, at present, a series of main gold jewelry brands also have silver jewelry, Miao silver jewelry their products on the improvement of impact of direct.

2, the development of payment and security system of the online store is still not perfect, need enterprise devoted more energy.
\end{abstract}

Potential entrants to the 1, although in 2008 the Miao silver is being established as the intangible cultural heritage, but have the Patent Technology competition pressure Co., some styles only silversmith old oral face-to-face, difficult to protect the heavy forging process technology.

2 , one of the characteristics of the product is purely hand-made, family workshops small cost also can produce.

According to the present situation, the main structure of Tianjin jewelry market, as shown in figure 4:

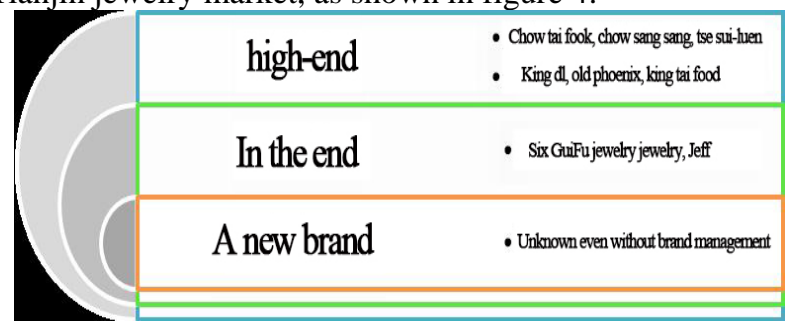

Figure 4. The main structure of Tianjin jewelry market

According to Zhou Dafu internal analysis report shows that in 2013 these brands in Tianjin market share, as shown in figure 5:

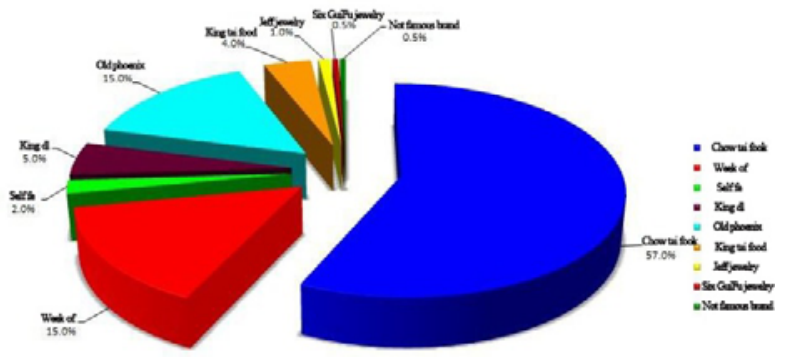

Figure 5. Tianjin jewelry market the brand market share

Gold and silver jewelry industry to enter the threshold is very low, the current several brand competition is not fierce, famous brand only Zhou Dafu, Xie Ruilin, Zhou Shengsheng etc.. In Tianjin market, these "similar" enterprises, stores often in Binjiang Road, peace road and King Street, XX shopping plaza in downtown lots, the annual profit of nearly one million yuan. For example, XX gold and silver jewelry to buy wheat shopping plaza only 10 square meters and counters, annual profits of up to 


\section{MARKET ENVIRONMENT ANALYSIS (SWOT ANALYSIS)}

TABLE 2 "MiaO SILVER" PROJECT SWOT ANALYSIS TABLE

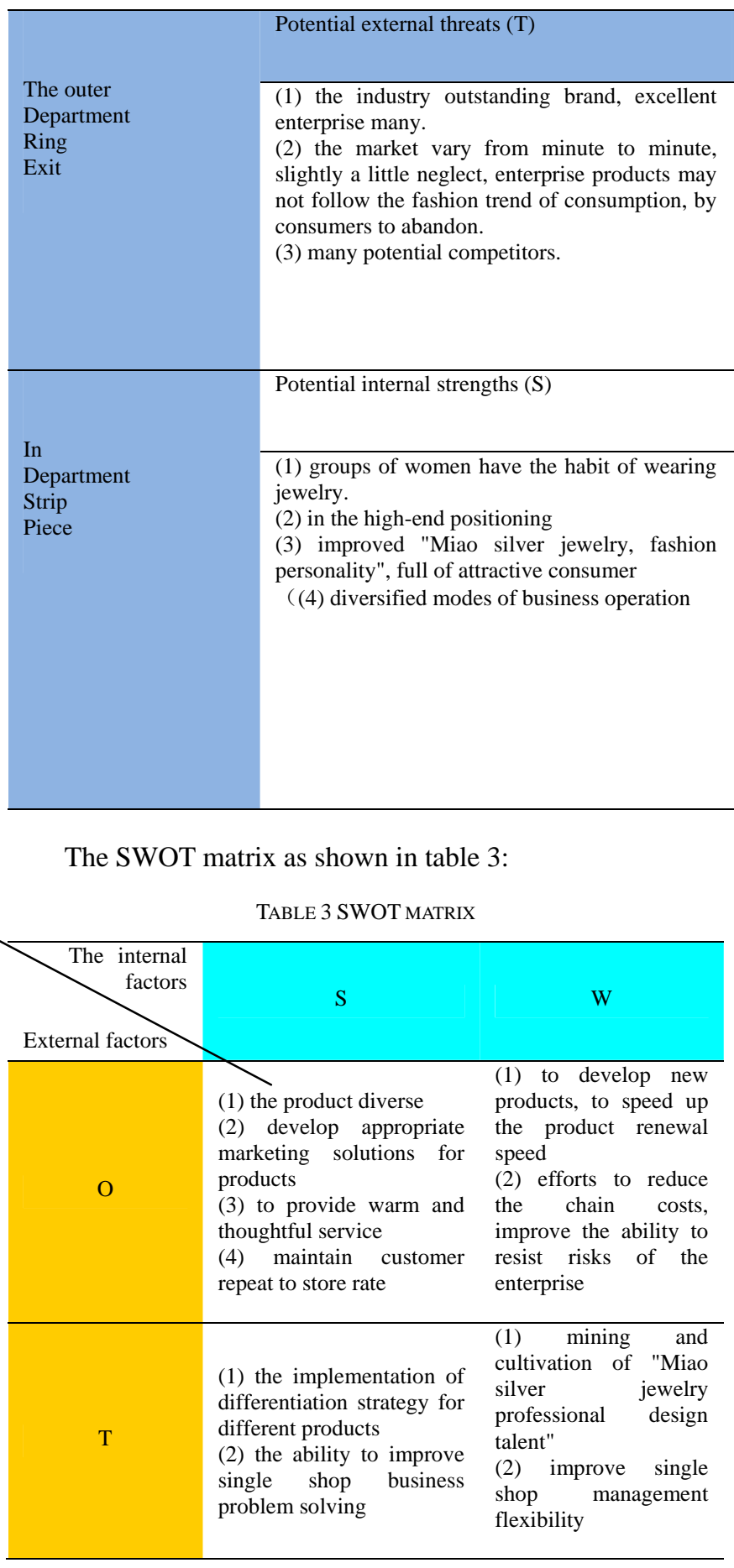

Use the opportunity to fully rely on the advantage, overcome the disadvantage, meet the challenge, can use the
Potential external opportunities $(\mathrm{O})$

(1) since the reform and opening up, Chinese rapid economic development, people's living standards improve, people gradually to complete or substantially to meet the physical needs of the consumer, to the pursuit of a higher level of consumption.

(2) people generally begin to small amount of investment, almost no threshold. These conditions are greatly contributed to the people for the gold and silver jewelry consumption. If enterprises can seize the opportunity of the era, to catch the wave tide, the enterprise can develop better and faster. (3) Tianjin is one of the four municipalities directly under the central government of China, rapid economic development. Food per capita living standard, most people realize the well-off level.

Potential internal weaknesses (W)

(1) the consumer contact information channel region with numerous, demand trend and volatility, as the seller, has slightly carelessly easy backlog of old. (2) "Miao silver jewelry" is the main origin of "Miao Autonomous Region", the relative distance, higher transportation costs, if the seller will this part addition in the price, "Miao silver jewelry will" lack of price competitive advantage.

(3) the local gold and silver jewelry many brands, market competition is intense, the well-known brands are numerous, both transnational giants (such as Tiffany\&Co) also local "tough guy" (Zhou Dafu and Zhou Shengsheng), "Miao silver jewelry" to gain a foothold, hand need plenty of capital; need rich and professional marketing experience on the other hand.

\section{following SO strategy:}

(1) The questionnaire shows: Tianjin consumers think "Miao silver" has a rich ethnic customs, without losing the avant-garde fashion, some pure handmade jewelry favored by consumers. "Miao silver" cultural background, manufacturing process, make its unique collection value. Rely on mining "Miao silver" historical and cultural connotation, can achieve diversification in varieties, multi-level, the unique national style and cultural background of the combination is bound to create new in order to be different but very popular brand products.

(2) In Tianjin and the silver and the gold jewelry market, advantages and threats, "Miao silver" project the future should fully strengthen the cost advantages, expand the product line, improve jewelry production, using a series of marketing tools, to increase sales. At the same time, the adjustment of Miao silver jewelry products structure, extensive acquisition of traditional Miao silver jewelry, refurbished or do the old, have some innovation and breakthrough in the product.

(3) The gold and silver jewelry industry technical content is limited, once the first to eat crab people open the market, follow the master of professional talents, it is bound to the formation of transcendence. Visible, professional design talent is the industry's advantage, especially cultivate their own professional talent, is the key in this industry based, or even maintain advantage. The implementation of 
the "talents" strategy, actively and the art college approached, the introduction of professional design talent, to set up a scholarship in colleges to foster its own professional design staff, the implementation of brand strategy from the design, to become the domestic first-class brand.

\section{CONCLUSION}

Through the above analysis of silver market opportunities and Miao, visible "benefit" the opportunity is rare. Research on the feasible market opportunities can allow enterprises to effectively seize the opportunity. At the same time, if you are able to model the form of industry and save even Miao silver forging process prosperity endangered, such research valuable and meaningful.

\section{REFERENCES}

[1] Alexander Ostwald (Alexander Osterwalder) (Sweden). Eve. Pinie (Yves Pigneur) (Belgium). The business mode of the new generation [M]. Beijing: Mechanical Industry Press, 2011 October

[2] Fan Xiucheng, Chen Jie [J]. brand image comprehensive evaluation model and its application in Nankai journal, 2002, (3).

[3] Wu Xiaoyun, Zhang Feng. A model of the relationship of global service marketing strategic dimensions and antecedents: An Empirical Study of the [J]. science research management, 220 companies based on 2009, (6).

[4] Griffin, Owen Steen. Li Wenxiang. How to win back customers [M]. Beijing: Tsinghua University press, 2006

[5] Liu Shizhong. Brand planning practice [M]. Shanghai: Fudan University press, 2007

[6] E. David Baer. Translated by Zhang Yongqiang. The strategy of retail and management $[\mathrm{M}]$. Jilin: Publishing House of Dongbei University of Finance and Economics.2000. 2010.6(3): 51-58.

[7] Ying Cao, at the country group, Chen Junsong. The consumer evaluations of brand extension: the impact of user image [J]. Journal of marketing science, 2010.6 (3): 51-58.

[8] Markides, Constantinos C. Game-Changing Strategies: How to Create New Market Space in Established Industries by Breaking the Rules. san Francisco: Jossey-Bass.2008.

[9] Markides, Constantinos C. Game-Changing Strategies: How to Create New Market Space in Established Industries by Breaking the Rules. San Francisco: Jossey-Bass.2008. 